\title{
AIR PERMEABILITY OF SUGI (CRYPTOMERIA JAPONICA) WOOD IN THE THREE DIRECTIONS
}

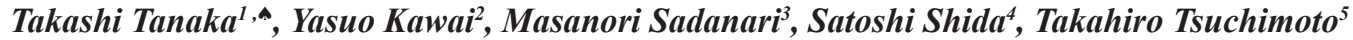

\begin{abstract}
To investigate the air permeability of sugi (Cryptomeria japonica) and the effect of grain directions on it, the air permeabilities of air-dried sugi sapwood and heartwood were determined along the three material directions of wood. The value of the longitudinal permeability was the highest and that of the radial permeability was the lowest. The permeability of heartwood was about an order of magnitude less than the permeability of sapwood in the same direction. The ratio between the tangential and radial permeability was approximately 10 , which was similar to softwoods that have impermeable rays. These results suggest that sugi has ray tissues that are either impermeable or have very low permeability. The radial permeability of sugi was much lower than that of Pinus, Sequoia, Juniperus, Abies and Tsuga measured with gases reported in the literature, indicating that sugi is one of the least radially permeable softwoods. These findings explain the reasons for the difficulties encountered in the drying and chemical treatment of sugi (Cryptomeria japonica).
\end{abstract}

Keywords: Air permeability, Japanese cedar, radial permeability, tangential permeability, sugi.

\section{INTRODUCTION}

Permeability refers to the conductivity of a porous medium with respect to fluid migration under the influence of a pressure gradient (Perré 2007). Bulk flow in wood, such as impregnation of wood with stabilizers, preservatives, and pulping agents, and diffusion, such as drying or fumigation, are interrelated to wood permeability levels (Siau 1995). Good permeability in wood may lead to faster, cheaper, and higher-quality drying, easier chemical treatment, and effective manufacturing of woodpolymer composites. Permeability strongly depends on the wood species and grain directions (Siau 1995).

Many studies have revealed the permeability of various softwoods such as Pinus (Choong and Fogg 1968, Perré 1987), Picea (Perré 1987), Larix (Matsumura et al. 1994), Pseudotsuga (Tanaka et al. 2010), Abies (Lihra et al. 2000), Tsuga (Kawabe and Mori 1981, Kawabe and Mori 1985, Rayirath and Avramidis 2008), Sequoia (Resch and Echlund 1964, Choong and Fogg 1968), Chamaecyparis (Kawabe and Mori 1981, Kawabe and Mori 1985), and Juniperus (Choong and Fogg 1968). All these data were measured with gases and with dried wood specimens. Some of these studies were summarized by Comstock (1970) and Perré (2007).

Sugi (Cryptomeria japonica), which is the only species of the genus Cryptomeria, is endemic to Japan and is the most common wood species in Japanese forests. In 2011, the volume of sugi production was 9,65 million $\mathrm{m}^{3}$, which was $53 \%$ of the total volume of all the softwood and hardwood production in Japan (MAFF 2013). The moisture content of sugi is over 100\% on average even in heartwood (Nakada et al. 1998), which makes implementation of fast, high-quality drying of sugi difficult.

\footnotetext{
${ }^{1}$ Graduate School of Agriculture, Shizuoka University. Ohya, Suruga-ku, Shizuoka 422-8529, Japan ${ }^{2}$ Institute of Wood Technology, Akita Prefectural University. Kaieizaka. Noshiro 016-0876, Japan

${ }^{3}$ Woodworking \& Coating, Polytechnic University. Ogawa Nishi-Machi, Kodaira-shi, Tokyo 187-0035, Japan

${ }^{4}$ Graduate School of Agricultural and Life Sciences, University of Tokyo. Yayoi, Bunkyo-ku, Tokyo 113-8657, Japan

${ }^{5}$ Department of Building Materials and Components, Building Research Institute. Tachihara, Tsukuba, Ibaraki 305-0802, Japan

Received: 16.11. 2013 Accepted: 10.02. 2014

•Corresponding author: attanak@ipc.shizuoka.ac.jp
} 
Kawabe and Mori (1981) determined the longitudinal air permeability of air-dried sugi sapwood and heartwood. Kawabe and Mori (1985) also determined the tangential air permeability of air-dried sugi sapwood and heartwood and calculated anisotropy ratio between the longitudinal and tangential permeabilities. Matsumura et al. (1994) have shown the longitudinal air permeability of sugi sapwood, heartwood, and intermediate wood. Fujii et al. (1997) have shown the longitudinal air permeability of almost oven-dried sugi sapwood and heartwood. Nagai and Taniguchi (2001) investigated the internal pressures in green sugi logs subjected to vacuum and concluded that the radial permeability of green sugi sapwood is lower than its tangential permeability. However, to the best of our knowledge, no literature is available on the actual radial permeability value of dried sugi.

To investigate the permeability of sugi and the effect of grain directions, we determined the air permeability of small blocks of air-dried sugi sapwood and heartwood along the three material directions.

\section{Theory}

Given that permeability is independent of the length of the specimen in the flow direction (Siau 1995), Darcy's law with regard to a fluid (a gas or a liquid) in a porous medium is expressed by the following equation.

$$
Q=\frac{k A \Delta P}{L}
$$

where $Q$ is the volumetric flow rate $\left(\mathrm{m}^{3} / \mathrm{s}\right), \mathrm{k}$ is the permeability to the fluid $\left(\mathrm{m}^{2} / \mathrm{Pa} \cdot \mathrm{s}\right), \mathrm{A}$ is the cross sectional area of the specimen $\left(\mathrm{m}^{2}\right), \Delta P$ is the pressure differential $(\mathrm{Pa})$, and $L$ is the length of the specimen $(\mathrm{m})$ in the flow direction.

Specific permeability is the product of permeability and the viscosity of the fluid and, since these quantities are inversely proportional, specific permeability should remain the same regardless of the fluid used (Siau 1995). By using the following equation, the permeability to the fluid $\mathrm{k}$ can be converted to specific permeability $K\left(\mathrm{~m}^{2}\right)$, which is an intrinsic value of the porous medium.

$$
K=k \mu
$$

where $\mu$ is the viscosity of the fluid (Pa $\cdot \mathrm{s})$.

\section{MATERIALS AND METHODS}

Three sugi trees were harvested in Saitama Prefecture, Japan. A $50 \mathrm{~mm}$ thick disk was cut at four different heights, namely 0,$1 ; 2,15 ; 4,2$ and 6,25 meters from each tree. Six cylindrical wood specimens $21 \mathrm{~mm}$ in diameter were taken from each disk. Four of them were $3 \mathrm{~mm}$ thick for the radial (R) and tangential (T) flow experiments, and the other two specimens were $10 \mathrm{~mm}$ thick for the longitudinal (L) flow experiments (Figure 1). Half of the specimens were obtained from sapwood and the other half were obtained from heartwood. 

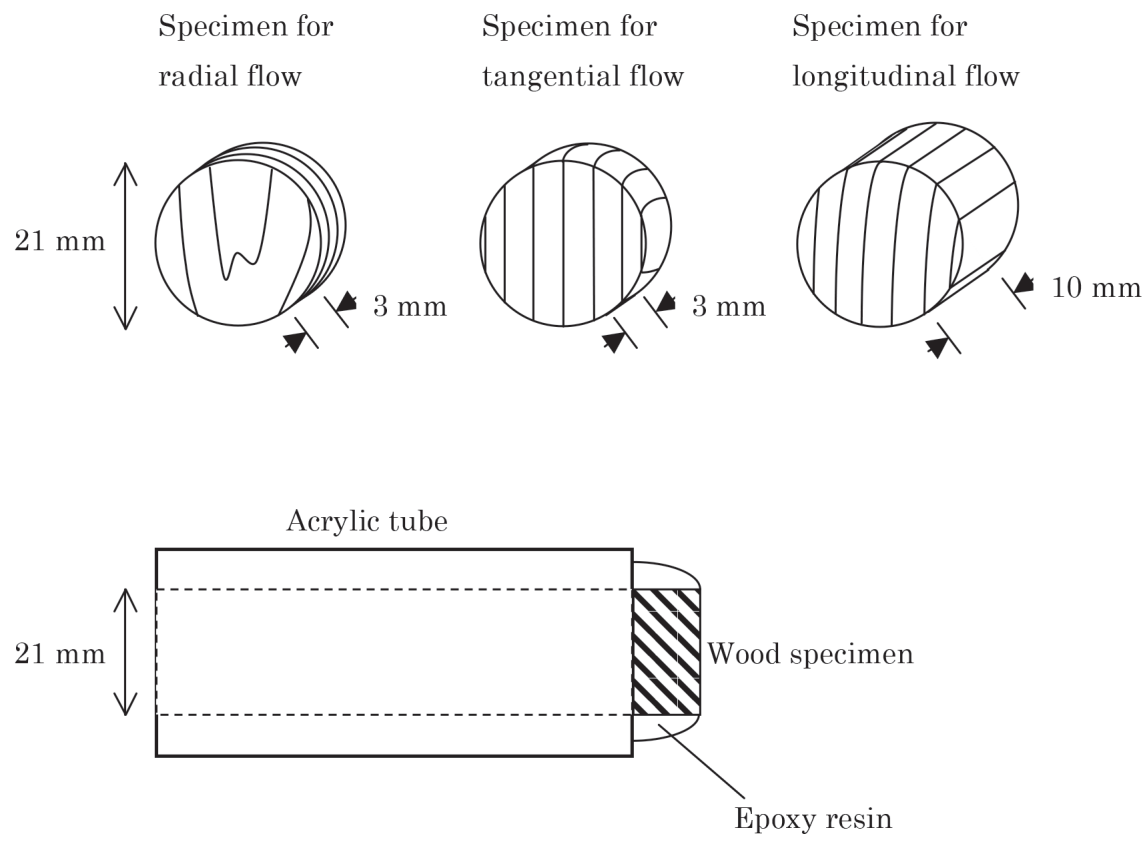

Figure 1. Schematic of experimental samples.

All the cylindrical wood specimens were dried in a climate chamber at $20{ }^{\circ} \mathrm{C}$ and $65 \%$ relative humidity. After drying, the specimens were glued on acrylic tubes $21 \mathrm{~mm}$ in inner diameter with epoxy resin (Quick Set 30, Konishi Co. Ltd., Tokyo), as shown in figure 1.

The longitudinal air permeability was measured by using the apparatus shown in figure 2 by the Falling Water Displacement Method (FWDM) explained by Siau (1995). The air permeability $\left(k_{g}\right)$ was calculated with the equations (3) and (4), as suggested by Siau (1995). The inner radius of the measuring tube was $13 \mathrm{~mm}, V r$ was taken as $0,00040 \mathrm{~m}^{3}, \bar{z}$ was taken as $0,5 \mathrm{~m}$, and $\Delta z$ was $0,1 \mathrm{~m}$. The duration from $z=0,55$ to $z=0,45$ was measured using a stopwatch as $t$.

$$
\begin{gathered}
k_{\mathrm{g}}=\frac{V_{\mathrm{d}} C L\left(P_{\mathrm{atm}}-0,074 \bar{z}\right)}{t A(0,074 \bar{z})\left(P_{\mathrm{atm}}-0,037 \bar{z}\right)} \times \frac{0,760}{1,013 \times 10^{5}} \\
C=1+\frac{V_{\mathrm{r}}(0,074 \Delta z)}{V_{\mathrm{d}}\left(P_{\mathrm{atm}}-0,074 z\right)}
\end{gathered}
$$

where $V_{d}$ is the volume of the gas $\left(\mathrm{m}^{3}\right)$ displaced by water in displacement tube, $C$ is the correction factor for gas expansion, $P_{a t m}$ is the barometric pressure $(\mathrm{mHg}), \bar{z}$ is the average height of water $(\mathrm{m})$ over the surface of the reservoir during the period of measurement, $t$ is the time (s), $V_{r}$ is the gas volume $\left(\mathrm{m}^{3}\right)$ remaining in the system at the completion of the gas flow period, $\Delta z$ is the change in the height of water (m) during time $t$, and $z$ is the height of the water column (m) above the reservoir at time $t$. 


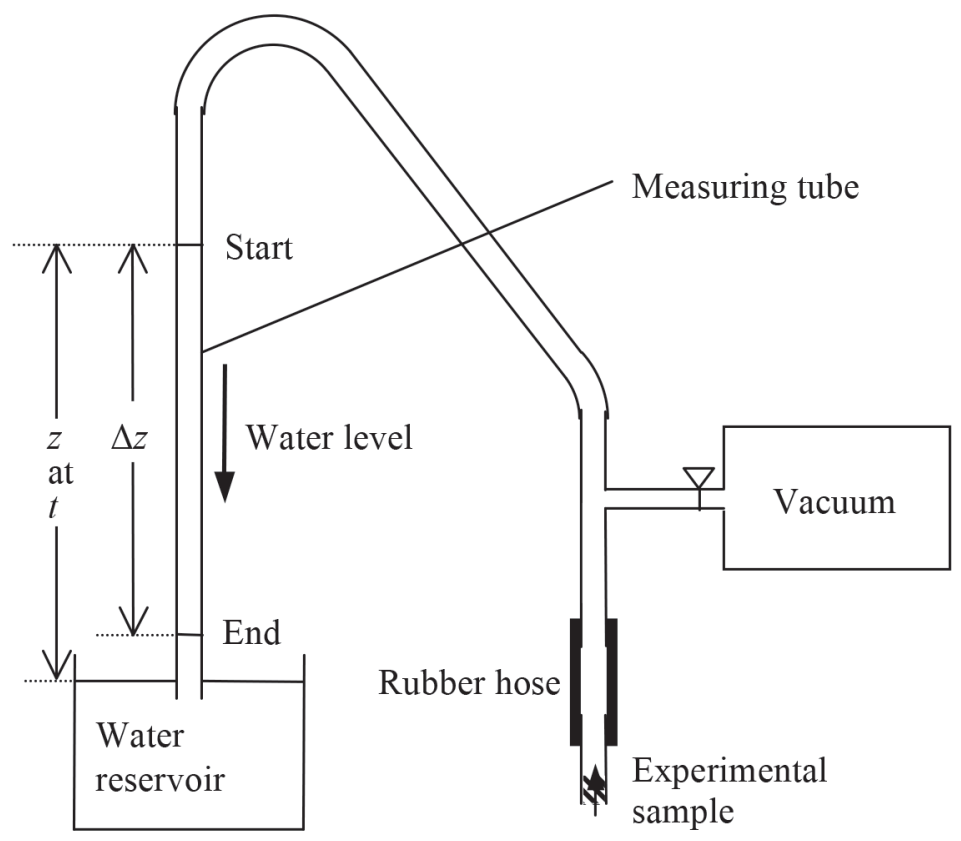

Figure 2. Schematic of the apparatus used for measuring longitudinal air permeability.

The radial and tangential air permeabilities were measured by using the apparatus shown in figure 3 by a method similar to the Rising Water Displacement Method (RWDM) explained by Siau (1995). $k_{g}$ was calculated with the equations (5) and (6), as suggested by Siau (1995). The inner radius of the measuring tube was $3 \mathrm{~mm}$. About $0,22 \mathrm{mHg}(300 \mathrm{hPa})$ was exerted as the pressure differential between the pressure meters $\mathrm{P} 1$ and $\mathrm{P} 2$ at the beginning of the measurement. The measurement was carried out for approximately 300 seconds.

$$
\begin{gathered}
k_{\mathrm{g}}=\frac{C V_{\mathrm{d}} L\left(P_{\text {atm }}-0,074 \bar{z}\right)}{t A(\Delta P-0,074 \bar{z})\left(P_{\text {atm }}-\frac{\Delta P}{2}-0,037 \bar{z}\right)} \times \frac{0,760}{1,013 \times 10^{5}} \\
C=1+\frac{V_{\mathrm{r}}\left(0,074 \Delta z+6,00 \times 10^{-5} \frac{\mu_{\mathrm{w}}(\Delta z)^{2}}{r^{2} t}\right)}{V_{\mathrm{d}}\left(P_{\text {atm }}-0,074 z\right)}
\end{gathered}
$$

where $\Delta P$ is the pressure differential $(\mathrm{mHg}$ ) between the pressure meters $\mathrm{P} 1$ and $\mathrm{P} 2$ at the beginning of the measurement, $\mu_{w}$ is the viscosity of water (Pa.s), and $r$ is the inner radius (m) of the measuring tube. 


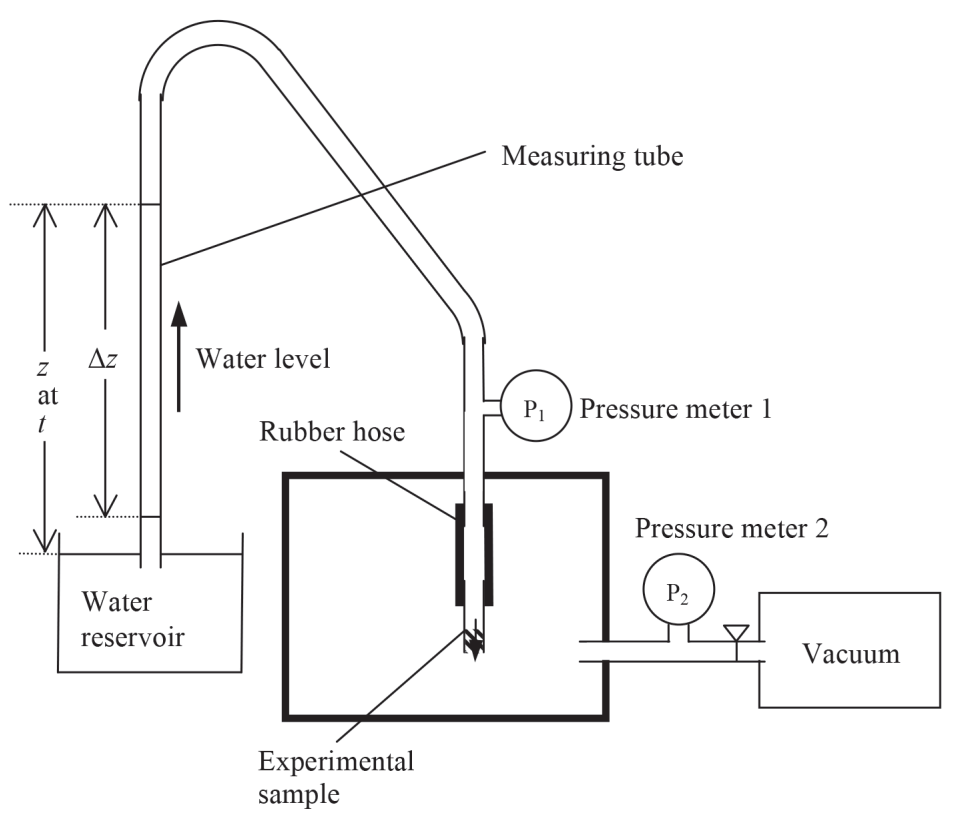

Figure 3. Schematic of the apparatus used for measuring radial and tangential air permeability.

All the obtained permeability values were converted to specific permeability using equation (2) and $1,81 \times 10^{-5}(\mathrm{~Pa} \cdot \mathrm{s})$ for the viscosity of air at $20^{\circ} \mathrm{C}($ Siau 1995$)$. 


\section{RESULTS AND DISCUSSION}

Figure 4 shows the histograms of the specific permeabilities of sapwood and heartwood in the three material directions. The permeability values showed large variations in each direction, differing by more than one order of magnitude. The value of the longitudinal permeability was the highest and that of the radial permeability was the lowest. The permeability of heartwood was about an order of magnitude less than the permeability of sapwood in the same direction.
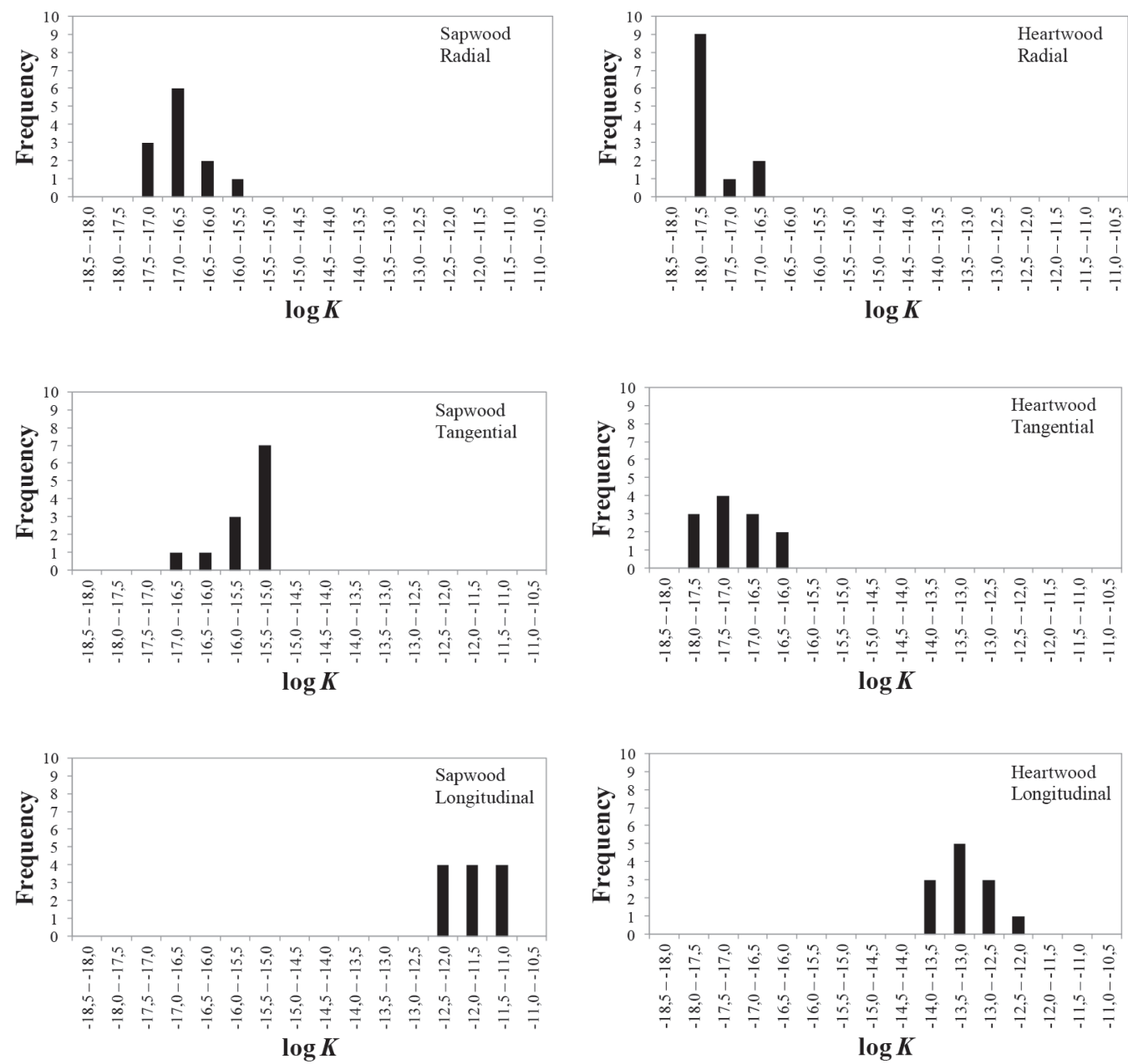

Figure 4. Histograms of sapwood and heartwood specific permeability values along the three material directions.

Table 1 shows the mean, standard deviation, median, and anisotropy ratio of the specific permeability values. The radial permeability was about an order of magnitude less than the tangential permeability. The trend is similar to that noticed in Sequoia sempervirens, Juniperus virginiana and Pseudotsuga menziesii (Choong and Fogg 1968), but different from the trends shown in Pinus spp. (Choong and Fogg 1968, Comstock 1970). Considering that Sequoia sempervirens, Juniperus virginiana and Pseudotsuga menziessii generally have impermeable rays (Siau 1995), while Pinus have open ray structure (Siau 1995), the results obtained from the present study suggest that sugi has impermeable or very little permeable ray tissues. 
Table 1. Specific permeabilities of sugi sapwood and heartwood along the three material directions.

\begin{tabular}{|c|c|c|c|c|c|c|c|c|}
\hline \multirow{2}{*}{ Wood type } & \multirow{2}{*}{ Direction } & \multirow{2}{*}{$\mathrm{N}$} & \multicolumn{3}{|c|}{ Permeability $\times 10^{-12} \quad\left(\mathrm{~m}^{2}\right)$} & \multicolumn{3}{|c|}{ Mean anisotropy ratio } \\
\hline & & & Mean & Std. dev. & Median & $/ \mathrm{L}$ & $/ \mathrm{R}$ & $/ \mathrm{T}$ \\
\hline \multirow{3}{*}{ Sapwood } & $\mathrm{L}$ & 12 & 2,4 & 1,8 & 2,3 & - & 83000 & 6700 \\
\hline & $\mathrm{R}$ & 12 & 0,000030 & 0,000034 & 0,000012 & 0,000012 & - & 0,081 \\
\hline & $\mathrm{T}$ & 12 & 0,00037 & 0,00028 & 0,00034 & 0,00015 & 12 & - \\
\hline \multirow{3}{*}{ Heartwood } & $\mathrm{L}$ & 12 & 0,12 & 0,12 & 0,059 & - & 23000 & 7500 \\
\hline & $\mathrm{R}$ & 12 & 0,0000053 & 0,0000083 & 0,0000021 & 0,000044 & - & 0,33 \\
\hline & $\mathrm{T}$ & 12 & 0,000016 & 0,000016 & 0,0000085 & 0,00013 & 3,1 & - \\
\hline
\end{tabular}

Figure 5 compares the mean radial specific permeability of sugi determined in the present study and that of other softwoods measured with gas (Resch and Echlund 1964, Choong and Fogg 1968, Comstock 1970, Kawabe and Mori 1985, Perré 1987, Lihra et al. 2000, Perré 2007, Tanaka et al. 2010). Here, the permeability of Tsuga heterophylla was calculated according to the equation suggested by Kawabe and Mori (1985) for a sample thickness of $3 \mathrm{~mm}$. The radial air permeability of sugi was much lower than that of Pinus, Sequoia, Juniperus, Abies and Tsuga; whereas, the value was marginally higher than that of Pseudotsuga. 

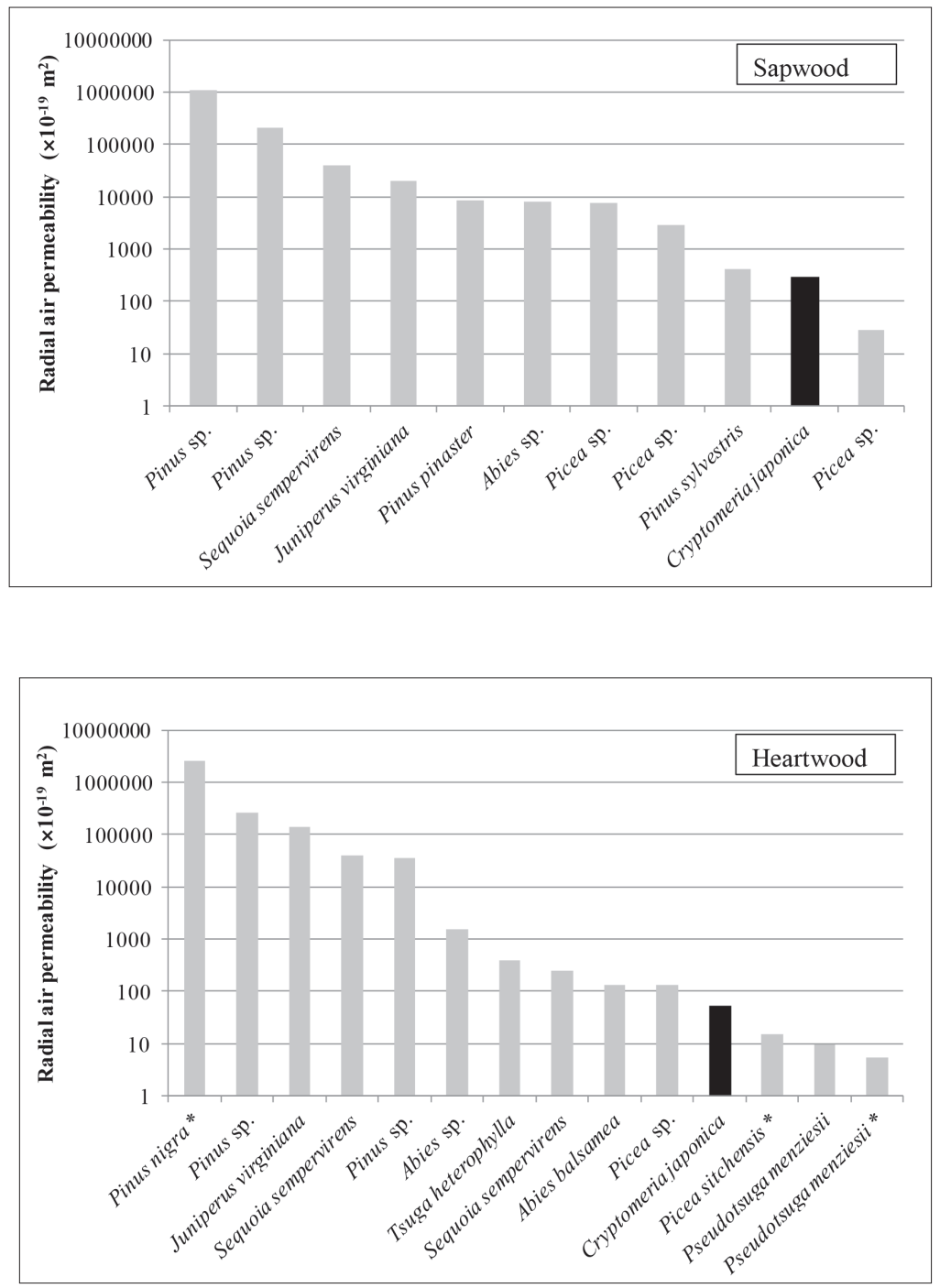

Figure 5. Comparison of the mean radial specific permeability of sugi (Cryptomeria japonica) and other softwoods.

The symbol * indicates that the moisture content is unknown.

Figure 6 compares the mean tangential specific permeability of sugi determined in the present study and that of other softwoods measured with gas (Resch and Echlund 1964, Choong and Fogg 1968, Comstock 1970, Kawabe and Mori 1985, Lihra et al. 2000, Tanaka et al. 2010). Here, the permeabilities of Cryptomeria japonica, Tsuga heterophylla Chamaecyparis obtusa and Chamaecyparis taiwanensis were calculated according to the equation suggested by Kawabe and Mori (1985) for a sample thickness of $3 \mathrm{~mm}$. The tangential permeability of sugi measured in the present study is the same in the order of magnitude as that measured in the previous study. The tangential air permeability of sugi was lower than that of Pinus, Sequoia, Juniperus, Abies and Tsuga. 

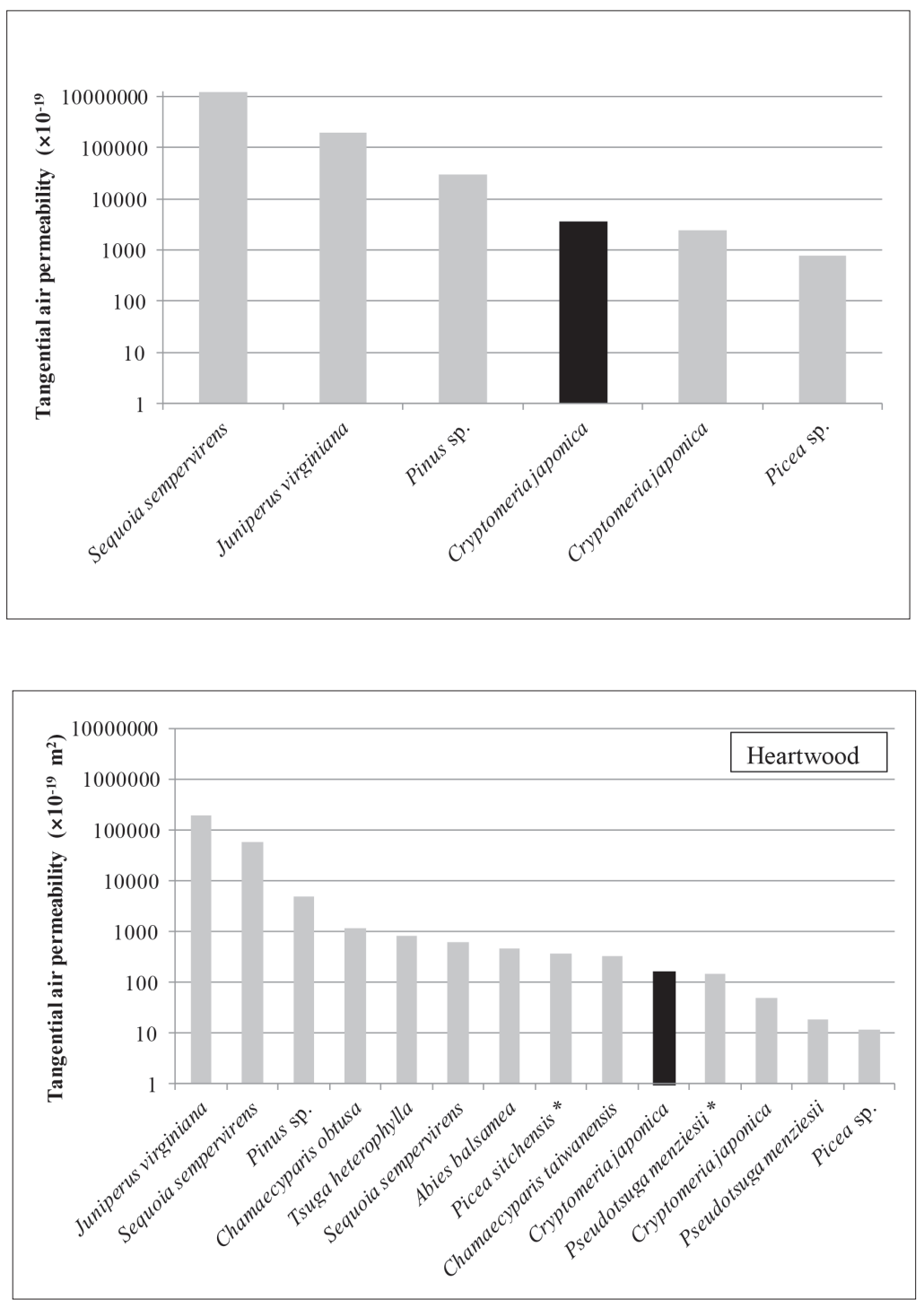

Figure 6. Comparison of the mean tangential specific permeability of sugi (Cryptomeria japonica) and other softwoods.

The symbol * indicates that the moisture content is unknown.

Figure 7 compares the mean longitudinal specific permeability of sugi determined in the present study and that of other softwoods measured with gas (Resch and Echlund 1964, Choong and Fogg 1968, Comstock 1970, Kawabe and Mori 1981, Perré 1987, Matsumura et al. 1994, Fujii et al. 1997, Lihra et al. 2000, Perré 2007, Tanaka et al. 2010). Here, the permeabilities of Cryptomeria japonica, Tsuga heterophylla Chamaecyparis obtusa and Chamaecyparis taiwanensis were calculated according to the equation suggested by Kawabe and Mori (1981) for a sample thickness of $10 \mathrm{~mm}$. The longitudinal permeability of sugi measured in the present study is the same in the order of magnitude as that measured in the previous studies. The longitudinal air permeability of sugi was not lower than that of Pinus, Juniperus, Abies, Chamaecyparis, Picea and Tsuga, which is a very different trend from that of the radial and tangential directions. 

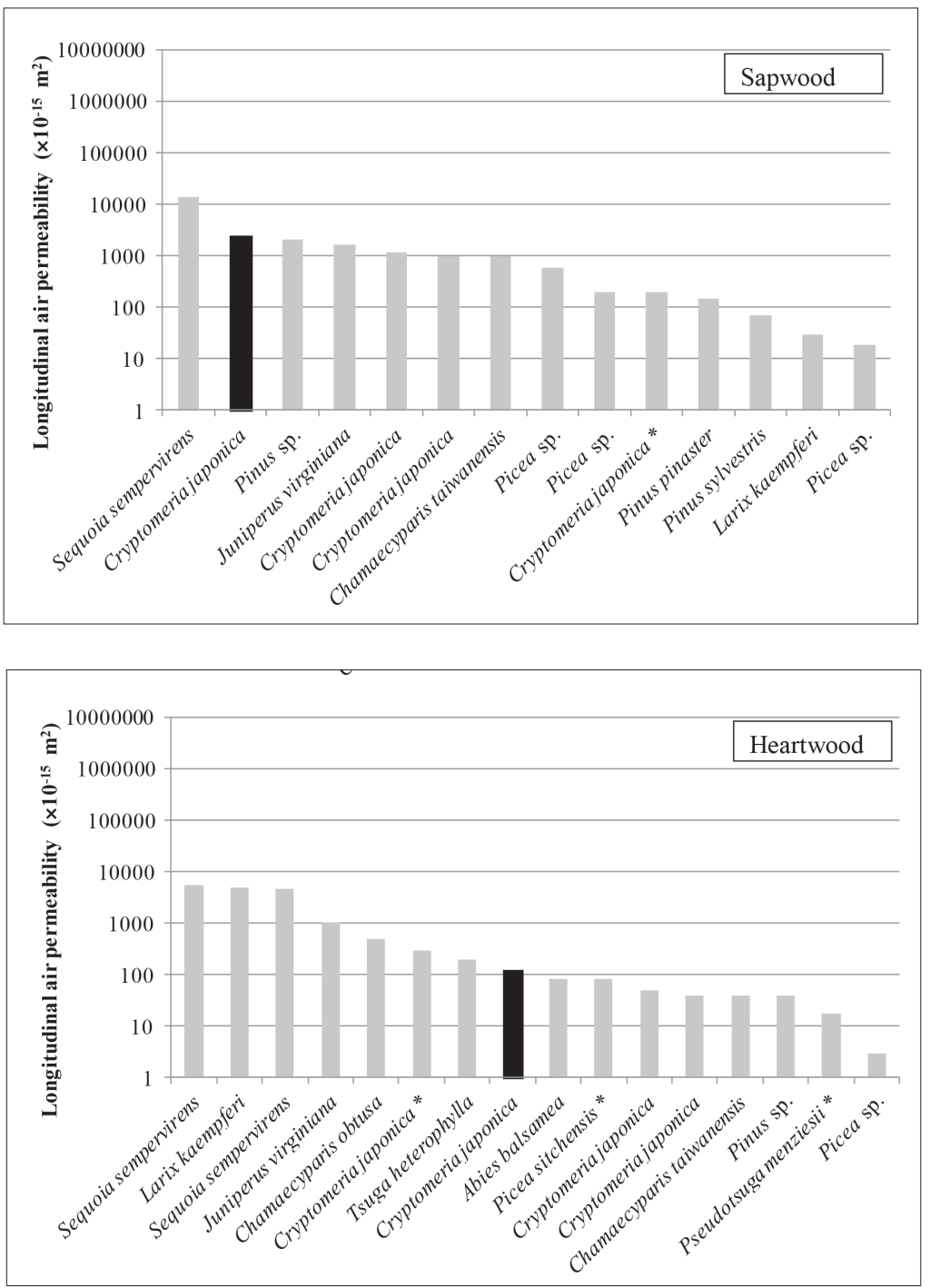

Figure 7. Comparison of the mean longitudinal specific permeability of sugi (Cryptomeria japonica) and other softwoods.

The symbol * indicates that the moisture content is unknown.

Overall, these results indicate that sugi is one of the least transversally permeable softwoods especially in the radial direction, which could contribute to the difficulties encountered in the drying and chemical treatment of sugi. The low permeability of sugi will remain as one of the key issues in the Japanese wood industry as long as sugi is the commercially most important wood species in Japan. 


\section{CONCLUSIONS}

We determined the air permeabilities of air-dried sugi sapwood and heartwood along the three material directions of wood. The major findings were as follows:

The value of the longitudinal permeability was the highest and that of the radial permeability was the lowest.

The permeability of heartwood was about an order of magnitude less than the permeability of sapwood in the same direction.

The anisotropy ratio between the tangential and radial permeability was found to be approximately 10. This results suggest that sugi has impermeable or very little permeable ray tissues.

The radial permeability of sugi was much lower than that of Pinus, Sequoia, Juniperus, Abies and Tsuga, indicating that sugi is one of the least radially permeable softwoods.

\section{ACKNOWLEDGMENT}

This study was supported by a research grant from the Ministry of Land, Infrastructure, Transport and Tourism (MLIT), Japan.

\section{REFERENCES}

MAFF. Ministry of Agriculture, Forestry and Fisheries. 2013. Annual report on forest and forestry in Japan (Fiscal year 2012). Japan.

Choong, E. T.; Fogg, P. J. 1968. Moisture movement in six wood species. For Prod J 18(5): 66-70.

Comstock, G. L. 1970. Directional permeability of softwoods. Wood Fiber Sci 1(4): 283-289.

Fujii, T.; Suzuki, Y.; Kuroda, N. 1997. Bordered pit aspiration in the wood of Cryptomeria japonica in relation to air permeability. IAWA $J$ 18(1): 69-76.

Kawabe, J.; Mori, M. 1981. Longitudinal air permeability in fifteen wood species (in Japanese). Zairyo 30(334): 666-672.

Kawabe, J.; Mori, M. 1985. Transverse air permeability in fifteen wood species (in Japanese). Zairyo 34(383): 918-924.

Lihra, T.; Cloutier, A.; Zhang, S. Y. 2000. Longitudinal and transverse permeability of balsam fir wet wood and normal heartwood. Wood Fiber Sci 32(2): 164-178.

Matsumura, J.; Tsutsumi, J.; Oda, K. 1994. Relationships of bordered pit aspiration to longitudinal gas permeability in a given stem level: preliminary discussion on air-dried wood of Cryptomeria japonica and Larix leptolepis (in Japanese). Bull Kyushu Univ For 71: 35-46.

Nagai, S.; Taniguchi, Y. 2001. Air permeability in wood of Cryptomeria japonica D. Don: air permeability in heartwood, white zone wood and sapwood in green logs (in Japanese). Zairyo 50(4): 409-414. 
Nakada, R.; Fujisawa, Y.; Hirakawa, Y.; Yamashita, K. 1998. Longitudinal change of the green moisture content in the stem of Cryptomeria japonica D. Don (in Japanese). Mokuzai Gakkaishi 44(6): 395-402.

Perré, P. 1987. Measurements of softwoods' permeability to air: importance upon the drying model. Int Commun Heat Mass Transf 14: 519-529.

Perré, P. 2007. Fluid migration in wood. In: Perré, P. (ed) Fundamentals of wood drying. A.R.BO. LOR., Nancy, pp. 125-156.

Rayirath, P.; Avramidis, S. 2008. Some aspects of western hemlock air permeability. Maderas. Ciencia y tecnología 10(3): 185-193.

Resch, H.; Echlund, B. A. 1964. Permeability of wood-exemplified by measurements on redwood. For Prod J 14(5): 199-206.

Siau, J. F. 1995. Permeability. In: Siau, J. F. (ed) Wood: influence of moisture on physical properties. Virginia Polytechnic Institute and State University, Blacksburg, pp. 39-58.

Tanaka, T.; Shida, S.; Avramidis, S. 2010. A preliminary study on ultrasonic treatment effect on transverse wood permeability. Maderas. Ciencia y tecnología 12(1): 3-9. 